\title{
Hemolytic-uremic syndrome in Switzerland: a nationwide surveillance 1997-2003
}

\author{
Alexandra Schifferli • Rodo O. von Vigier • \\ Matteo Fontana • Giuseppina Spartà • Hans Schmid • \\ Mario G. Bianchetti • Christoph Rudin • \\ The Swiss Pediatric Surveillance Unit (SPSU)
}

Received: 23 June 2009 /Revised: 14 September 2009 /Accepted: 22 September 2009/Published online: 15 October 2009

(C) Springer-Verlag 2009

\begin{abstract}
Hemolytic-uremic syndrome (HUS) is a leading cause of acute renal failure in childhood. In its typical presentation, it is preceded by an episode of diarrhea mostly due to Shiga-toxin-producing Escherichia coli. There is important geographical variation of many aspects of this syndrome. Nationwide data on childhood HUS in Switzerland have not been available so far. In a prospective national study through the Swiss Pediatric Surveillance Unit 114 cases (median age 21 months, 50\% boys) were reported between April 1997 and March 2003 by 38 pediatric units (annual incidence 1.42 per $10^{5}$ children $\leq 16$ years). Shiga-toxinproducing E. coli were isolated in $32(60 \%)$ of tested stool samples, serotype O157:H7 in eight. Sixteen children
\end{abstract}

Swiss Pediatric Surveillance Unit Committee: Ch. Aebi, Berne (President); V. Bernet-Büttiker, Zurich; P. Hüppi, Geneva; B.

Laubscher, Neuchâtel; Ch. Rudin, Basel; H. Zimmermann, Berne; D. Beeli, Berne.

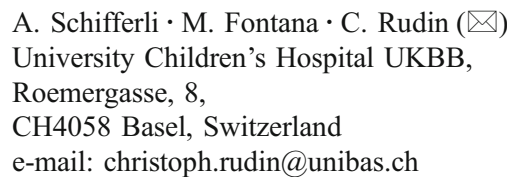

R. O. von Vigier

University Children's Hospital,

Berne, Switzerland

G. Spartà

University Children's Hospital,

Zurich, Switzerland

H. Schmid

Federal Office of Public Health (FOPH),

Berne, Switzerland

M. G. Bianchetti

Division of Pediatrics, Ospedale San Giovanni,

Bellinzona, Switzerland presented with only minimal renal involvement, including three with underlying urinary tract infection. Six patients presented with atypical hemolytic-uremic syndrome, and six with HUS due to invasive Streptococcus pneumoniae infection. Mortality was $5.3 \%$, including two out of six children with $S$. pneumoniae infection. The severity of thrombocytopenia and the presence of central nervous system involvement significantly correlated with mortality. In conclusion, childhood HUS is not rare in Switzerland. Contrasting other countries, E. coli $\mathrm{O} 157: \mathrm{H} 7$ play only a minor role in the etiology. Incomplete manifestation is not uncommon.

Keywords Hemolytic-uremic syndrome - Children . Enterohemorrhagic E. coli (EHEC) - Shiga toxin ·

Renal failure $\cdot$ Clinical spectrum

$\begin{array}{ll}\text { Abbreviations } \\ \text { HUS } & \text { hemolytic-uremic syndrome } \\ \text { D+ HUS } & \text { typical HUS (enteropathic or non-enteropathic) } \\ \text { D- HUS } & \text { atypical HUS } \\ \text { cHUS } & \text { complete HUS } \\ \text { iHUS } & \text { incomplete HUS } \\ \text { Stx } & \text { Shiga toxin } \\ \text { EHEC } & \text { enterohemorrhagic Escherichia coli } \\ \text { NENT } & \text { Swiss National Centre for Enteropathogenic } \\ & \text { Bacteria } \\ \text { SPSU } & \text { Swiss Pediatric Surveillance Unit } \\ \text { STEC } & \text { Shiga-toxin-producing Escherichia coli } \\ \text { UTI } & \text { urinary tract infection } \\ \text { CI } & \text { confidence interval }\end{array}$

\section{Introduction}

Childhood hemolytic-uremic syndrome (HUS) is not very frequent but mostly a severe multisystem disorder charac- 
terized by microangiopathic hemolytic anemia, thrombocytopenia, and acute renal impairment. It is associated with significant morbidity and mortality, including acute and chronic renal failure and long-term multi-organ complications in a substantial number of affected children. In its typical (D+ HUS), mostly enteropathic form, childhood HUS occurs after a prodromal episode of usually bloody diarrhea caused by a Shiga toxin (Stx)-producing pathogen, most commonly enterohemorrhagic Escherichia coli (Stxproducing EHEC $=$ STEC), worldwide primarily of serotype O157:H7. However, other serotypes are increasingly reported $[15,25]$ as well. On average, enteropathic HUS appears six (5-10) days after the onset of gastrointestinal symptoms and affects $3-9 \%$ (up to $20 \%$ in epidemic forms) of infected children [3,6]. Risk factors for the development of HUS include young age, bloody diarrhea, fever, elevated leukocyte count, elevated C-reactive protein, as well as treatment with antimotility agents, antibiotics, and non-steroidal anti-inflammatory drugs $[1,4,8,17,36]$. Elevated leukocyte count, severe gastrointestinal prodromi, early anuria, and age below 2 years are considered predictors of a severe course [26].

More rarely, STEC cause a typical, but non-enteropathic HUS in the context of an extra-intestinal, mostly urinary tract infection (UTI) [16, 29].

Finally, in some patients, the clinical presentation is not related to diarrhea and/or Stx-producing pathogens; these forms have formerly been referred to as atypical HUS (D- HUS). The etiology of $\mathrm{D}^{-}$HUS is diverse, including other infections, disorders of complement regulation, von Willebrand proteinase deficiency, and more [5, 9, 10, 21]. As infection with Streptococcus pneumoniae represents another major infectious cause of non-Stx-associated HUS these cases should be classified separately.

Despite these general characteristics, several studies indicate important geographical variation of clinical, epidemiological, and microbiological features of this syndrome. So far, some single center data $[18,20]$, but no systematic report on the characteristics of childhood HUS have been available for Switzerland. This was the reason to undertake this study between April 1997 and March 2003, using the SPSU, an ongoing national surveillance system.

\section{Methods}

The SPSU was established in 1995 to assess epidemiological and clinical features of selected rare childhood diseases leading to hospitalization. It is operated under the auspices of the Swiss Pediatric Society and the Swiss Federal Office of Public Health. The surveillance period for HUS lasted from April 1, 1997, to March 31, 2003. Cases were defined as children $\leq 16$ years of age with: (1) acute hemolytic anemia,
(2) microscopic evidence of red blood cell fragmentation, (3) thrombocytopenia (platelet count $\leq 150 \times 10^{9} / \mathrm{L}$ ), and (4) acute renal impairment (urinalysis disclosing either (a) red blood cells, cellular casts, and pathological proteinuria or (b) dysmorphic red cells and pathological proteinuria, with or without (c) creatinine levels above the upper limit of normal for age, or an increase in creatinine of $\geq 50 \%$ above baseline). HUS was diagnosed based on the presence of at least three criteria or two criteria plus isolation of a Stxproducing pathogen.

SPSU reply cards have been sent to all Pediatric Units of Swiss Hospitals at monthly intervals. For each reported case, the respective hospital was provided with a detailed standardized questionnaire. Patients who did not meet the case definitions were rejected. A follow-up questionnaire was sent to the treating physician after 1 year.

Cases with preceding diarrhea (enteropathic) and/or evidence of Stx-producing pathogens in cultures of stool, urine, or blood were classified as typical HUS (D+ HUS). Patients with $S$. pneumoniae-associated HUS were classified separately and the remaining non-Stx-associated cases were referred to as atypical (D- HUS). HUS was moreover referred to as complete (cHUS) in children who fulfilled the above-mentioned serum creatinine definition of renal impairment and as incomplete (iHUS) if the renal impairment manifested only with proteinuria and/or hematuria or a mild documented rise in serum creatinine level $(<50 \%$ over baseline). If available, stool samples of children with enteropathic HUS were processed for STEC in the Swiss National Center for Enteropathogenic Bacteria (NENT) [12].

Significance between groups was determined by Student's $t$ test, by one-way analysis of variance (ANOVA) with Bonferroni multiple comparison post test, and corresponding non-parametric tests as appropriate for continuous, and Fisher's exact test for categorical variables. Results are expressed as mean \pm standard deviation (SD) or as median with range. Qualitative parameters are given as a proportion (percentage). Two-sided tests were used throughout, and $P$ values $<0.05$ were considered statistically significant.

\section{Results}

Between April 1997 and March 2003, all SPSU reply cards and HUS questionnaires were returned (100\%). A total of 114 HUS patients (median age 21 months; range 20 days to 13 years; 57 girls and boys, each) were identified. One hundred patients $(88 \%)$ were $\leq 5$ years old. Typical and atypical HUS accounted for $102(89 \%)$ and six (5\%) cases, respectively, and in six $(5 \%)$ patients HUS was due to invasive infection with $S$. pneumoniae. The disease was complete in $98(86 \%)$ and incomplete in 16 (14\%) children. The average annual 
incidence was 1.42 cases (range, 0.61-1.92) per 100,000 children $\leq 16$ years of age.

Typical versus atypical and pneumococcal HUS

HUS was typical in 102 children, including 99 with enteropathic and 3 with non-enteropathic forms as a consequence of a STEC-associated UTI. In contrast to typical HUS, which predominantly occurred during the warm season with 70/102 cases (69\%) diagnosed between May and September, nine of 12 atypical and S. pneumoniae-associated cases (75\%) occurred between October and April $(P<0.01)$.

STEC were isolated in $32 / 53$ stool samples $(60 \%)$ examined by the NENT. In three children with UTIassociated HUS, STEC were isolated from the urine and also from a blood culture in one. Eighteen different serotypes were identified, including $\mathrm{O} 157: \mathrm{H} 7$ in eight, $\mathrm{O} 145: \mathrm{H} 25$ in five, O26:H11 in four, and O55:H7 in three samples; the remaining 14 serotypes were identified only once or twice, each. Although serotype O157:H7 was the most frequently isolated serotype, it only accounted for eight of 35 (23\%) classified pathogens. In 11 additional children with typical, enteropathic HUS STEC were identified by private laboratories but not further differentiated.

There was no association between isolation of $E$. coli O157:H7 and presentation or clinical course of the disease. Bloody diarrhea was present in $75 \%$ of those with and $46 \%$ of those without O157:H7 isolation, respectively. Dialysis became necessary in $13 \%$ and $39 \%$ of these groups, respectively. There was no fatality among children with O157:H7 isolation. O157:H7 was even found in one patient with incomplete HUS, however, complicated by severe intussusception in this case.

Shiga toxin production was documented in 37 of 102 patients with D+ HUS. Unfortunately, the number of samples being tested for Stx is not known. Stx1 was found in seven, Stx 2 in 23, and both in seven patients. There was no association of either type with complete or incomplete forms of the disease.

In six children the disease was the consequence of an infection with $S$. pneumoniae. In one previously reported patient the disease complicated an acute infectious mononucleosis [28], while in two patients atypical HUS occurred as a consequence of cobalamin $\mathrm{C}$ disease and factor $\mathrm{H}$ deficiency, respectively. Classification was not possible in the remaining three patients.

\section{Complete versus incomplete HUS}

Hemolytic-uremic syndrome was incomplete in 16/114 (14\%) patients. They presented with acute hemolytic anemia, evidence of red blood cell fragmentation, and altered urinalysis. Thrombocytopenia was present in 12 children. However, these children did not fulfill the case definition with regard to their serum creatinine levels. Hemolytic-uremic syndrome was typical in 14 patients with iHUS, including 11 with enteropathic forms (bloody diarrhea in five) and three with UTI. Duration of prodromal diarrhea was longer in iHUS compared to cHUS (10 days versus 5 days, $P<0.01)$. STEC were isolated in five of seven examined fecal specimens (serotype O157:H7 in one case), both not significantly different from cHUS. Private laboratories disclosed Shiga-toxin-producing E. coli in two further children. No stool sample was available in two cases with an incomplete form of enteropathic HUS. Additionally, in children with iHUS anemia and thrombocytopenia were significantly $(P<0.01)$ less pronounced than in children with cHUS (Table 1). Accordingly, blood transfusions were significantly less often needed $(P<0.01)$ in patients with iHUS as compared to those with cHUS. Finally (Table 1 ), in iHUS the duration of hospital stay was significantly shorter compared to survivors with cHUS ( 9 versus 16 days, $P<0.01)$ and neurological involvement was less frequent $(P<0.05)$. One girl with O157:H7-associated iHUS developed intussusception requiring surgical intervention.

\section{HUS associated with urinary tract infection}

The causative infection was localized in the urinary tract in three children with iHUS. All presented with an acute febrile UTI without any evidence of an intestinal infection. These patients presented with microangiopathic hemolytic anemia and thrombocytopenia; two of them additionally with arterial hypertension. An underlying malformation of the urinary tract was found in one patient.

\section{Mortality}

Six patients died (Table 2), corresponding to an overall mortality of $5.3 \%$. All had suffered from cHUS. None of the patient with atypical HUS (D-) died. A causative infectious agent was identified in three children $(S$. pneumoniae in two, STEC in one). The highest mortality $(2 / 6=33 \%)$ was observed for HUS associated with invasive $S$. pneumoniae infection $(P<0.05)$. Five of the six patients with a fatal outcome $(83 \%)$ had suffered from severe neurological symptoms, as compared to $18 \%$ of survivors with cHUS. Thus, in the presence of severe neurological symptoms, the relative risk of fatal outcome was 17.3 (95\% CI, 2.1-140.3, $P<0.01)$. In contrast to the survivors with cHUS (platelet count, $46 \pm 45 \times 10 \mathrm{E}^{9} /$ l), patients who died presented with more severe thrombocytopenia (platelet count, $\left.12 \pm 10 \times 10 \mathrm{E}^{9} / 1 ; P<0.01\right)$. Using arbitrary cut-offs in these patients, thrombocytopenia below $20 \times 10 \mathrm{E}^{9} / 1$ and below $12 \times 10 \mathrm{E} 9 / 1$ were associated with a relative risk for fatal outcome of 10.5 (95\% CI, 1.3-86.0, $P<0.05)$ and 14.0 (95\% CI, 2.9-68.4, $P<0.01$ ), respectively. 


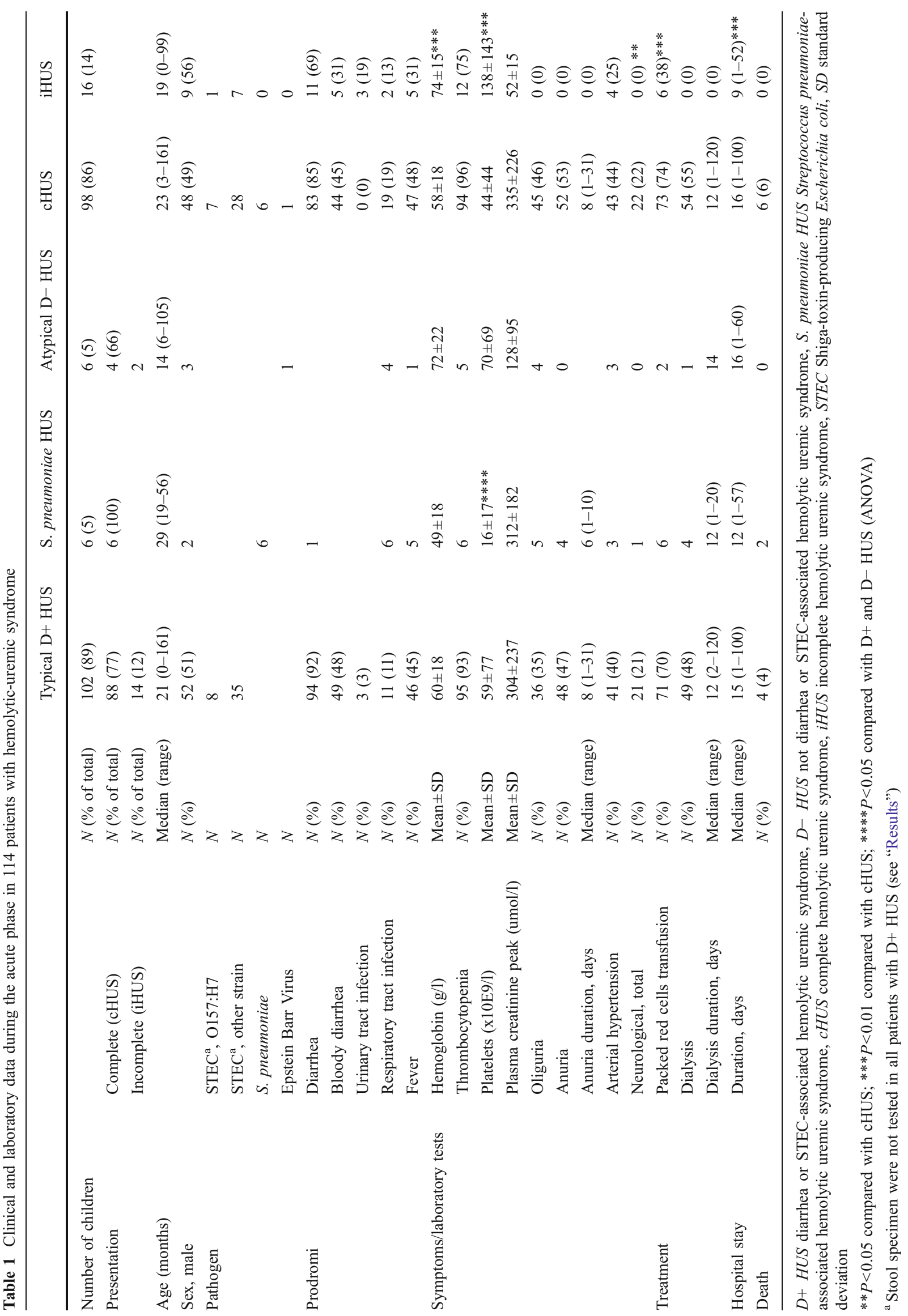


Table 2 Clinical and laboratory data in six patients with fatal outcome from hemolytic-uremic syndrome

\begin{tabular}{|c|c|c|c|c|c|c|c|c|c|}
\hline & & & Total & Patient 1 & Patient 2 & Patient 3 & Patient 4 & Patient 5 & Patient 6 \\
\hline Presentation & & & & $\mathrm{D}+$ & $\mathrm{D}+$ & $\mathrm{D}+$ & S. pneumoniae & S. pneumoniae & $\mathrm{D}+$ \\
\hline Age (months) & & Median & 21 & 3 & 11 & 15 & 26 & 56 & 58 \\
\hline Sex & & & & Male & Female & Female & Female & Female & Female \\
\hline \multirow[t]{2}{*}{ Pathogen } & STEC & $N$ & 1 & & $\mathrm{O} 145: \mathrm{H} 25$ & & Yes & Yes & \\
\hline & S. pneumoniae & $N$ & 2 & & & & & & \\
\hline \multirow[t]{4}{*}{ Prodromi } & Diarrhea & $N$ & 5 & Yes & Yes & Yes & No & Yes & Yes \\
\hline & Bloody diarrhea & $N$ & 2 & No & Yes & No & No & No & Yes \\
\hline & $\begin{array}{l}\text { Respiratory tract } \\
\text { infection }\end{array}$ & $N$ & 4 & No & No & Yes & Yes & Yes & Yes \\
\hline & Fever & $N$ & 3 & No & No & Yes & Yes & Yes & No \\
\hline \multirow{8}{*}{$\begin{array}{l}\text { Symptoms/laboratory } \\
\text { tests }\end{array}$} & Hemoglobin (g/l) & Median & 61 & 40 & 117 & 12 & 40 & 81 & 111 \\
\hline & Platelets (x10E9/1) & Median & 9 & 4 & 31 & 8 & 6 & 10 & 14 \\
\hline & $\begin{array}{l}\text { Plasma creatinine } \\
\quad(\mu \mathrm{mol} / 1)\end{array}$ & Median & 291 & 437 & 295 & 252 & 199 & 237 & 270 \\
\hline & Oliguria & $N$ & 6 & Yes & Yes & Yes & Yes & Yes & Yes \\
\hline & Anuria & $N$ & 5 & Yes & Yes & Yes & No & Yes & Yes \\
\hline & Arterial hypertension & $N$ & 3 & Yes & No & Yes & No & Yes & No \\
\hline & Neurological symptoms & $N$ & 5 & Seizure & Comma & Seizure & - & Disoriented & Seizure \\
\hline & Cerebral CT imaging & & & $\begin{array}{l}\text { Ischemic } \\
\text { encephalopathy }\end{array}$ & $\begin{array}{l}\text { Cortical } \\
\text { necrosis }\end{array}$ & $\begin{array}{l}\text { Edema, } \\
\text { bleeding }\end{array}$ & & $\begin{array}{l}\text { Edema, } \\
\text { meningitis }\end{array}$ & Infarction \\
\hline \multirow[t]{2}{*}{ Treatment } & $\begin{array}{l}\text { Packed red cells } \\
\text { transfusion }\end{array}$ & $N$ & 5 & Yes & Yes & Yes & Yes & Yes & No \\
\hline & Dialysis & $N$ & 5 & PD & $\mathrm{PD}$ & $\mathrm{PD} / \mathrm{HD}$ & No & No & $\mathrm{PD}$ \\
\hline
\end{tabular}

$P D$ peritoneal dialysis, $H D$ hemodialysis; for abbreviations of D+ HUS, D- HUS, and S. pneumoniae, please see footnote Table 1

\section{One-year follow-up}

Of a total of 108 survivors, $80(74 \%)$ had a reported 1-year follow-up examination, including 74/98 (76\%) of the $\mathrm{D}+$ HUS, four of six $(67 \%)$ of the D- HUS, and two of four $(50 \%)$ of the $S$. pneumoniae groups, respectively.

Among the children with D+ HUS persistent renal impairment was reported for $13(18 \%)$ and end-stage renal failure requiring dialysis for four $(5 \%)$ children. Twelve patients $(16 \%)$, including five with normal renal function, suffered from persistent arterial hypertension. One patient had persistent hematuria. Other complications were recurrent bloody diarrhea in four $(5 \%)$ and seizures in three patients (4\%; all with renal impairment). Rare complications such as endocrine and exocrine pancreatic insufficiency with insulin-dependent diabetes, reactive arthritis after an $E$. coli 0157:H7 infection and cardiomyopathy (with end-stage renal failure) were noted in one patient, each. One patient presented with residual hemiplegia in consequence of carotid artery thrombosis during the acute phase. Another patient was subject to laser therapy because of retinal bleeding.

In the subgroup of D- HUS two patients $(50 \%)$ were in end-stage renal failure ( $P<0.05$, compared to D+ HUS), one suffered from HUS relapses. Two children (50\%) were treated for isolated arterial hypertension. No other rare complications were reported. No sequelae were reported by the two patients with $S$. pneumoniae-associated HUS.

Ten questionnaires were received from patients who initially suffered from iHUS $(n=16)$. The only long-term consequence reported by these patients was recurrence of bloody diarrhea in one case.

Clinical and laboratory presentation during the acute phase was similar in children with normal renal function at follow-up, compared to those with chronic kidney disease and reduced glomerular filtration after 1 year.

Only the need for transfusion was significantly associated with reduced renal function at 1 year $(P<0.05)$; for the duration of dialysis (39 \pm 38 versus $10 \pm 4$ days) and the incidence of seizures (31\% versus 10\%) during the acute phase, the respective figures remained just below statistical significance $(P=0.06$ for both).

\section{Discussion}

Hemolytic-uremic syndrome was first described by Gasser and coworkers in 1955 in Switzerland [14]. However, except some single center studies [18, 20], nationwide data on childhood HUS in Switzerland have not been available so far. This report summarizes the results of the first 
nationwide prospective cross-sectional study performed between April 1997 and March 2003 using the SPSU network. In addition to the widely established features [25], this study reveals some particular aspects of childhood HUS: enterohemorrhagic E. coli of serotype O157:H7 only play a minor role in etiology of HUS in Switzerland, and infection with this strain is not associated with the most severe courses of the disease. Fourteen percent of the patients presented with only minor renal involvement, including three patients in whom HUS was caused by a STEC-associated UTI. Finally, the degree of thrombocytopenia and severe neurological symptoms were significantly associated with the risk of fatal outcome, whereas young age was not associated with the severity of the disease.

HUS is associated with significant morbidity and mortality during the acute phase. It is a leading cause of acute renal failure and results in long-term renal and extra-renal complications in a substantial number of affected children. It consists of a heterogeneous group of hemolytic disorders and new insights into pathophysiology have demonstrated, that HUS represents one clinical manifestation of a broader spectrum referred to as thrombotic microangiopathy [31], characterized by injury to the vascular endothelium which can be triggered by a number of different etiologies. Our survey primarily focused on the description of epidemiological and clinical aspects of HUS in Switzerland, whereas rare etiologies of the disease in D- HUS were not systematically tracked. Furthermore, we chose the traditional classification into D+ and $\mathrm{D}-$ forms of the disease for the presentation of our data in order to allow comparison with data from other countries. Patients with $S$. pneumoniae-associated HUS were classified separately as a third group.

In accordance with most published reports $[2,15,26]$, the presentation of HUS in this study was typical (D+ HUS) in the majority of the patients (89\%); these cases occurred significantly more often during summertime. Nevertheless, EHEC were successfully isolated and characterized in only $60 \%$ of tested stool samples, an observation that has previously been reported. In addition to technical difficulties to identify EHEC serotypes [7], it is assumed that at clinical onset of HUS, the causative agent has started to disappear from the intestine resulting in negative stool samples in many patients [30]. In North America and worldwide $\mathrm{O} 157: \mathrm{H} 7$ is the predominant serotype of EHEC causing HUS [2]. However, in Australia [11], Germany, and Austria [15] non-0157 STEC strains were more common. In our study, we found similar results with O157:H7 accounting for only eight $(25 \%)$ of 32 positively tested stool samples and eight of $53(15 \%)$ of all tested specimens respectively [19], underlining the increasingly acknowledged burden of disease associated with non-O157 STEC. Additionally, it is evermore recognized that illness due to non-O157 STEC may be equivalent in severity to illness induced by E. coli $\mathrm{O} 157: \mathrm{H} 7$. Accordingly, in the present study we found no association between isolation of $E$. coli O157:H7 and presentation or clinical course of the disease.

In our database, $86 \%$ of the patients had major renal involvement (cHUS), 47\% required dialysis, and 65\% received packed red cell transfusion, data similar to previous reports $[2,15,26]$. It has been described that some patients develop hemolytic anemia and thrombocytopenia with little evidence of renal disease, whereas other children present with important renal disease comparatively associated with few hematological abnormalities [32]. The present study clearly reveals a distinct subgroup of patients with only minor renal involvement. These $14 \%$ of patients, referred to as suffering from iHUS (Table 1), also presented with significantly less pronounced hematological abnormalities and therefore less need for transfusion, less neurological involvement, and shorter duration of hospitalization. In contrast, prodromal diarrhea lasted significantly longer compared to patients with cHUS, presumably reflecting a less severe multisystem involvement. Otherwise there were no differences in frequency of bloody diarrhea or causative serotypes of $E$. coli between the two groups. The observed proportion of iHUS is likely to represent an underestimate since many such patients, especially in case of even milder forms are unlikely to reach the hospital, or even to be diagnosed. Of note, in a prospective study in Argentina the incidence of iHUS complicating bloody diarrhea was twice that of cHUS [22]. This is of particular importance because long-term follow-up examinations will be missed in unrecognized cases. There are only few reports describing the various features of iHUS, even in large surveys of cHUS; additionally the case definitions were not universally the same $[22,23,33]$. In rare cases, HUS can originate from UTI $[16,29]$; in three patients of this series, iHUS was consequence of a STEC-associated UTI. Some authors have suggested that antibiotics may aggravate enteropathic HUS [36]. In contrast, prompt initiation of antibiotic treatment is certainly crucial for a favorable outcome in STEC-associated UTI with consecutive HUS.

In a minority of patients, the clinical presentation of HUS is atypical (D- HUS), i.e. not related to enterocolitis and/or STEC-infection. The etiology of D- HUS is diverse, including infectious causes such as HIV and more rarely other viral agents, genetic abnormalities of complement regulatory proteins (complement factor $\mathrm{H}, \mathrm{I}, \mathrm{B}$, or $\mathrm{MCP}$ ), and von Willebrand proteinase deficiency $[5,9,10,21,24$, 35]. In this survey, six patients $(5 \%)$ presented with $\mathrm{D}^{-}$ HUS, and six patients had HUS due to $S$. pneumoniae infection. This figure is slightly higher than in other studies, which reported this association for $38-43 \%$ of non-STEC HUS [10]; this might support the impression of an increasing incidence of $S$. pneumoniae-associated HUS [34]. Other identified causes of D- HUS in this series were 
cobalamin $\mathrm{C}$ disease, factor $\mathrm{H}$ deficiency, and infectious mononucleosis in one patient each; for the remaining patients, the origin remained unexplained.

Many studies addressed the short- and long-term course and outcome of HUS. In summary, it is assumed that death or end-stage renal disease occurs in about $12 \%$ of D+ HUS and $25 \%$ of survivors demonstrate long-term renal sequelae [13], whereas prognosis in non-Stx-associated HUS seems to be even worse. Given the important methodological differences between studies, comparison proves difficult and the subject still remains controversial [13]. Age under 2 years [8], HUS due to E. coli O157:H7 [15], high leukocyte count $[15,17], \mathrm{D}-$ and pneumococcal HUS [9, 25], central nervous symptoms [13, 27], and the need of dialysis during the acute phase [13] have all been associated with a severe course and a worse long-term prognosis, respectively. We report on a highly significant association between both, severe thrombocytopenia and central nervous manifestations, with risk of death during the acute phase and a significant association between both, the need for transfusion and the long-term prognosis (renal function). Additionally, we observed a tendency towards worse outcome with signs of chronic kidney disease or even end-stage renal disease in children with longer duration of dialysis and in those with seizures. The small number of patients certainly prohibits firm interpretation of these observations and, therefore, further studies are mandatory. The overall mortality in this series was $5.3 \%$, similar to $3-5 \%$ reported in the literature $[15,25,26]$. Compared to D+ HUS (4\%), children with pneumococcal HUS (33\%) had a significantly higher mortality $(P<0.05)$, supporting the results of other studies that suggest a more severe acute course of HUS due to $S$. pneumoniae [10,34]. Children with iHUS showed no renal sequelae at 1 year after the acute disease. Whether this holds true for the long-term prognosis remains to be studied. In their review, Garg et al. [13] found an association between the severity of the acute illness and an adverse long-term outcome in children with D+ HUS. However, these authors found also several studies suggesting that patients with less severe forms of HUS may still demonstrate renal sequelae at follow-up, in several even after apparent complete recovery from acute HUS. These observations emphasize the necessity of long-term follow-up after HUS, even in case of mild acute disease or initial apparent complete recovery. Therefore, unless other data become available, we suggest, that children with iHUS also deserve careful long-term follow-up. In order to recruit these children for appropriate care, the awareness of these mild forms of HUS needs to be increased.

Taking the limitations of the cross-sectional design of this study, i.e. the limited number of patients and the short followup period, into account, we conclude that this first, prospective, national study on childhood HUS in Switzerland establishes robust clinical, epidemiological, and bacteriological data, emphasizing the need for further long-term studies, especially to identify children at risk for long-term sequelae after minor renal involvement or initial apparent complete recovery of acute disease.

Acknowledgment National Centre for Enteropathogenic Bacteria (NENT), Lucerne: A. Burnens, P. Boerlin, and H. Hächler

Conflicts of interest The authors declare that they have no conflicts of interest

\section{References}

1. Ake JA, Jelacic S, Ciol MA, Watkins SL, Murray KF, Christie DL, Klein EJ, Tarr PI (2005) Relative nephroprotection during Escherichia coli $\mathrm{O} 157: \mathrm{H} 7$ infections: association with intravenous volume expansion. Pediatrics 115(6):e673-e680

2. Banatvala N, Griffin PM, Greene KD, Barrett TJ, Bibb WF, Green JH, Wells JG (2001) The United States National Prospective Hemolytic Uremic Syndrome Study: microbiologic, serologic, clinical, and epidemiologic findings. J Infect Dis 183(7):1063-1070

3. Bell BP, Goldoft M, Griffin PM, Davis MA, Gordon DC, Tarr PI, Bartleson CA, Lewis JH, Barrett TJ, Wells JG et al (1994) A multistate outbreak of Escherichia coli O157:H7-associated bloody diarrhea and hemolytic uremic syndrome from hamburgers. The Washington experience. JAMA 272(17):1349-1353

4. Bell BP, Griffin PM, Lozano P, Christie DL, Kobayashi JM, Tarr PI (1997) Predictors of hemolytic uremic syndrome in children during a large outbreak of Escherichia coli O157:H7 infections. Pediatrics 100(1):E12

5. Besbas N, Karpman D, Landau D, Loirat C, Proesmans W, Remuzzi G, Rizzoni G, Taylor CM, Van de Kar N, Zimmerhackl LB, European Paediatric Research Group of HUS (2006) A classification of hemolytic uremic syndrome and thrombotic thrombocytopenic purpura and related disorders. Kidney Int 70 (3):423-431

6. Boyce TG, Swerdlow DL, Griffin PM (1995) Escherichia coli O157:H7 and the hemolytic-uremic syndrome. N Engl J Med 333 (6):364-368

7. Caprioli A, Tozzi AE, Rizzoni G, Karch H (1997) Non-O157 Shiga toxin-producing Escherichia coli infections in Europe. Emerg Infect Dis 3(4):578-579

8. Cimolai N, Carter JE, Morrison BJ, Anderson JD (1990) Risk factors for the progression of Escherichia coli O157:H7 enteritis to hemolytic-uremic syndrome. J Pediatr 116(4):589-592

9. Copelovitch L, Kaplan BS (2008) The thrombotic microangiopathies. Pediatr Nephrol 23(10):1761-1767

10. Copelovitch L, Kaplan BS (2008) Streptococcus pneumoniaeassociated hemolytic uremic syndrome. Pediatr Nephrol 23 (11):1951-1956

11. Elliott EJ, Robins-Browne RM, O'Loughlin EV, Bennett-Wood V, Bourke J, Henning P, Hogg GG, Knight J, Powell H, Redmond D, Contributors to the Australian Paediatric Surveillance Unit (2001) Nationwide study of haemolytic uraemic syndrome: clinical, microbiological, and epidemiological features. Arch Dis Child 85(2):125-131

12. Essers B, Burnens AP, Lanfranchini FM, Somaruga SG, von Vigier RO, Schaad UB, Aebi C, Bianchetti MG (2000) Acute community-acquired diarrhea requiring hospital admission in Swiss children. Clin Infect Dis. 31(1):192-196

13. Garg AX, Suri RS, Baroowman N, Rehman F, Matsell D, RosasArellano MP, Salvadori M, Haynes RB, Clark WF (2003) Long- 
term renal prognosis of diarrhea-associated hemolytic uremic syndrome: a systematic review, meta-analysis, and metaregression. JAMA 290(10):1360-1370

14. Gasser C, Gautier E, Steck A, Siebenmann RE, Oechslin R (1955) Hemolytic-uremic syndrome: bilateral necrosis of the renal cortex in acute acquired hemolytic anemia. Schweiz Med Wochenschr 85 (38-39):905-909

15. Gerber A, Karch H, Allerberger F, Verweyen HM, ZImmerhack1 LB (2002) Clinical course and the role of shiga toxin-producing Escherichia coli infection in the hemolytic-uremic syndrome in pediatric patients, 1997-2000, in Germany and Austria: a prospective study. J Infect Dis 186(4):493-500

16. Hassink RI, Zeerleder SS, Truttmann AC, Bianchetti MG (1997) Hemolytic-uremic syndrome after Escherichia coli urinary tract infection. Pediatr Infect Dis J 16(8):828

17. Ikeda $\mathrm{K}$, Ida $\mathrm{O}$, Kimoto $\mathrm{K}$, Takatorige $\mathrm{T}$, Nakanishi N, Tatara $\mathrm{K}$ (2000) Predictors for the development of haemolytic uraemic syndrome with Escherichia coli O157:H7 infections: with focus on the day of illness. Epidemiol Infect 124(3):343-349

18. Imoberdorf G, Bianchetti MG, Rossi E, Gugler E, Oetliker OH (1993) Hemolytic-uremic syndrome in children: a 19-year retrospective study. Schweiz Med Wochenschr 123(29):1439-1444

19. Johnson KE, Thorpe CM, Sears CL (2006) The erging clinical importance of non-O157 Shiga toxin-producing Escherichia coli. Clin Infect Dis 43(12):1587-1595

20. Kernland KH, Laux-End R, Truttmann AC, Reymond D, Bianchetti MG (1997) How is hemolytic-uremic syndrome in childhood acquired in Switzerland? Schweiz Med Wochenschr 127(29-30):1229-1233

21. Loirat C, Noris M, Fremeaux-Bacchi V (2008) Complement and the atypical hemolytic uremic syndrome in children. Pediatr Nephrol 23(11):1957-1972

22. López EL, Contrini MM, Devoto S, de Rosa MF, Graña MG, Aversa L, Gómez HF, Genero MH, Cleary TG (1995) Incomplete hemolytic-uremic syndrome in Argentinean children with bloody diarrhea. J Pediatr 127(3):364-367

23. Lopez EL, Diaz M, Grinstein S, Devoto S, Mendilaharzu F, Murray BE, Ashkenazi S, Rubeglio E, Woloj M, Vasquez M et al (1989) Hemolytic uremic syndrome and diarrhea in Argentine children: the role of Shiga-like toxins. J Infect Dis 160(3):469475

24. Noris M, Brioschi S, Caprioli J, Todeschini M, Bresin E, Porrati F, Gamba S, Remuzzi G, International Registry of recurrent and familial HUS/TTP (2003) Familial haemolytic uraemic syndrome and an MCP mutation. Lancet 362(9395):1542-1547

25. Scheiring J, Andreoli SP, Zimmerhackl LB (2008) Treatment and outcome of Shiga-toxin-associated hemolytic uremic syndrome (HUS). Pediatr Nephrol 23(10):1749-1760

26. Siegler RL, Pavia AT, Christofferson RD, Milligan MK (1994) A 20-year population-based study of postdiarrheal hemolytic uremic syndrome in Utah. Pediatrics 94(1):35-40

27. Siegler RL (1994) Spectrum of extrarenal involvement in postdiarrheal hemolytic-uremic syndrome. J Pediatr 125(4):511-518

28. Simonetti GD, Dumont-Dos Santos K, Pachlopnik JM, Ramelli G, Bianchetti MG (2003) Hemolytic uremic syndrome linked to infectious mononucleosis. Pediatr Nephrol 18(11):1193-1194

29. Starr M, Bennet-Wood V, Bigham AK, de Koning-Ward TF, Bordun AM, Lightfoot D, Bettelheim KA, Jones CL, RobinsBrowne RM (1998) Hemolytic-uremic syndrome following urinary tract infection with enterohemorrhagic Escherichia coli: case report and review. Clin Infect Dis 27(2):310-315

30. Tarr PI, Beill MA, Clausen CR, Watkins SL, Christie DL, Hickman RO (1990) Escherichia coli O157:H7 and the hemolytic uremic syndrome: importance of early cultures in establishing the etiology. J Infect Dis 162(2):553-556

31. Trachtman H (2008) Introduction: education teaching article series on hemolytic uremic syndrome. Pediatr Nephrol 23(9):1423-1424

32. Verweyen HM, Karch H, Allerberger F, Zimmerhack1 LB (1999) Enterohemorrhagic Escherichia coli (EHEC) in pediatric hemolytic-uremic syndrome: a prospective study in Germany and Austria. Infection 27(6):341-347

33. von Vigier RO, Offermann N, Beretta-Piccoli BC, Bianchetti MG (2000) Paucisymptomatic hemolytic uremic syndrome. Pediatr Nephrol 14(5):436-437

34. Waters AM, Kerecuk L, Luk D, Hag MR, Fitzpatrick MM, Gilbert RD, Inward C, Jones C, Pichon B, Reid C, Slack MP, Van't Hoff W, Dillon MJ, Taylor CM, Tullus K (2007) Hemolytic uremic syndrome associated with invasive pneumococcal disease: the United Kingdom experience. J Pediatr 151(2):140-144

35. Wolf G (2004) Not known from ADAM(TS-13) - novel insights into the pathophysiology of thrombotic microangiopathies. Nephrol Dial Transplant 19(7):1687-1693

36. Wong CS, Jelacic S, Habeeb RL, Watkins SL, Tarr PI (2000) The risk of the hemolytic-uremic syndrome after antibiotic treatment of Escherichia coli O157:H7 infections. N Engl J Med 342 (26):1930-1936 